\title{
Predictors of paroxysmal atrial fibrillation in patients undergoing aortic valve replacement
}

\author{
Maciej Banach, MD, PhD, aleksander Goch, MD, PhD, a Malgorzata Misztal, PhD, dacek Rysz, MD, PhD, \\ Ryszard Jaszewski, MD, PhD, ${ }^{\mathrm{c}}$ and Jan Henryk Goch, MD, PhD ${ }^{\mathrm{a}}$
}

Objective: Atrial fibrillation is one of the most common complications after cardiac surgery. This study evaluates the risk factors of paroxysmal atrial fibrillation in patients who underwent aortic valve replacement.

Methods: The study comprised 300 patients with aortic valve defects of either aortic stenosis $(\mathrm{n}=150)$ or regurgitation $(\mathrm{n}=150)$ who underwent aortic valve replacement. For each patient, 2-mode and Doppler echocardiographic examinations were performed in the preoperative period, early postoperative period, and long-term observation, and selected hemodynamic parameters were analyzed.

Results: Factors significantly associated with atrial fibrillation in patients with aortic stenosis were heart failure (odds ratio $=5.5$ ), age 70 years or more (4.5), low (3.9) and high body mass index (1.7), maximal transvalvular gradient (3.7), low left ventricular ejection fraction (5.1), end-systolic (2.9) and end-diastolic intraventricular septum thickness (1.5), and insignificant mitral regurgitation (1.9) in the preoperative period; and left ventricular ejection fraction (4.4) and end-systolic intraventricular septum thickness (1.8) in the early postoperative period. In the aortic regurgitation group, factors significantly associated with atrial fibrillation were age (1.8), left ventricular ejection fraction (3.7), left ventricular end-systolic diameter (1.7), end-diastolic intraventricular septum thickness (1.7), left atrium dimension (4.1) and insignificant mitral regurgitation (2.5) in the postoperative period; essential arterial hypertension (3.3), diabetes mellitus (2.6), and heart failure in the history (4.5) in the preoperative period; and left ventricular ejection fraction (1.9) and left atrium dimension (2.9) in the early postoperative period.

Conclusion: On the basis of the separated risk factors, all patients should be preoperatively classified to applicable groups of risk of postoperative atrial fibrillation appearance, and the prophylactic treatment should be administered in the group of patients with the highest risk. It may essentially decrease the rate of complications and deaths, and, consequently, the costs of postoperative medical care.

From the Department of Cardiology; ${ }^{\mathrm{a}} \mathrm{Sec}-$ ond Department of Family Medicine, ${ }^{\mathrm{c}}$ and Department of Cardiac Surgery, ${ }^{\mathrm{d}}$ Medical University of Lodz, Poland; and Chair of Statistics of University of Lodz, ${ }^{\mathrm{b}}$ Poland.

Received for publication June 2, 2007; revisions received Aug 8, 2007; accepted for publication Aug 17, 2007.

Address for reprints: Maciej Banach, MD, $\mathrm{PhD}$, Department of Cardiology, 1st Chair of Cardiology and Cardiac Surgery, Medical University of Lodz, Sterlinga 1/3; 91 425 Lodz, Poland (E-mail: m.banach@ termedia.pl).

J Thorac Cardiovasc Surg 2007;134:1569-76 $0022-5223 / \$ 32.00$

Copyright (C) 2007 by The American Association for Thoracic Surgery

doi:10.1016/j.jtcvs.2007.08.032
A trial fibrillation (AF), especially paroxysmal $\mathrm{AF}$, is one of the most common complications after cardiac surgery. According to various authors, it occurs with a frequency of $10 \%$ to $50 \%$, depending on the definition and diagnostic method. ${ }^{1}$ AF usually occurs 2 to 4 days after surgery and often returns during the first 30 days of the postoperative period. ${ }^{2,3}$ Recently, AF has been noted more often, probably because more patients undergo surgery in worse conditions, often associated with essential organic changes of heart. More postoperative arrhythmias are also connected with the broadening group of patients undergoing open procedures and thereby are the result of a reduction in contraindications. Suitable treatment and prevention of postoperative AF are important for patients' improved health and faster rehabilitation, and for reduced hospitalization costs resulting from shorter lengths of stay in the hospital. ${ }^{4,5}$ Despite the existence of unique guidelines 


\author{
Abbreviations and Acronyms \\ $\mathrm{AF} \quad=$ atrial fibrillation \\ AVR = aortic valve replacement \\ BMI = body mass index \\ EDIVST $=$ end-diastolic intraventricular septum \\ thickness \\ ESIVST $=$ end-systolic intraventricular septum \\ thickness \\ ICU = intensive care unit \\ LAd = left atrium dimension \\ LVEF = left ventricular ejection fraction
}

from the American Heart Association, European Society of Cardiology, and American College of Cardiology, there are still doubts related to the selection of the best antiarrhythmic drugs, timing of therapy, duration of treatment, and prevention of renewed occurrences. 6,7

Many authors have tried to evaluate the predictors of postoperative AF. On the basis of available studies, they singled out inter alia the following postoperative risk factors: left ventricle failure in the preoperative period, age more than 75 years, reoperation, intraoperative and postoperative catecholamines application, and respiratory failure. ${ }^{2,7-10}$

The aim of the study was to evaluate the risks factors of paroxysmal AF in patients who underwent aortic valve replacement (AVR).

\section{Materials and Methods Patient Population}

The study comprised 300 patients with significant isolated aortic valve defect caused by aortic stenosis $(n=150)$ or regurgitation ( $\mathrm{n}$ $=150$ ) who underwent AVR between 1999 and 2004 in the Department of Cardiac Surgery in Lodz, Poland. All study subjects signed the informed consent form before inclusion in the study. The study was approved by the local ethics committee.

The mean age of the patients was $61.5 \pm 5.4$ years; there were 143 men $(47.67 \%)$ and 157 women $(52.33 \%)$. The mean body surface area was $1.87 \pm 0.21$, body mass index (BMI) was 26.75 \pm 3.42 , and mean preoperative ejection fraction was $49.13 \% \pm$ $7.8 \%$. The following concomitant diseases were observed in this group of patients: arterial hypertension $(n=195 ; 64.7 \%)$, diabetes mellitus $(n=60 ; 20 \%)$, renal failure $(n=11 ; 3.67 \%)$, and severe heart failure with a left ventricular ejection fraction (LVEF) of $35 \%$ or less $(\mathrm{n}=51 ; 17 \%)$.

All patients with the following conditions were excluded from the study: aortic valve defect in the course of infective valve defect, aortic valve defect as a result of myocardial infarction complication, history of myocardial infarction or cerebrovascular event, history of cardiac surgery, 1-step surgery of other valve replacement/plastics and/or surgical revascularization, surgery in emergency/urgent mode, history of preoperative arrhythmias (eg, AF/flutter, ventricular arrhythmias, receiving antiarrhythmic drugs, including beta-blockers), or other significant coexistent conditions (eg, severe renal, pulmonary diseases, and neoplasms).
Each patient who qualified for the AVR underwent coronary angiography (on average $33 \pm 7.7$ hours before the surgery, range 19-63 hours), and no significant changes in coronary arteries were found. For each patient included in the study, 2-mode and Doppler echocardiographic examinations were performed in the preoperative period (up to 48 hours before the operation), in the early postoperative period (4-21 days after surgery; on average after 9 days), and in long-term observation as a follow-up examination (18-24 months after the surgery; on average after 21 months). The following echocardiographic parameters were evaluated: LVEF, left ventricular end-systolic and end-diastolic diameters, endsystolic intraventricular septum thickness (ESIVST), end-diastolic intraventricular septum thickness (EDIVST), left atrium dimension (LAd), and mean and maximal transvalvular gradients for patients with aortic stenosis. All investigations were performed on Philips Hewlett Packard Sonos 2000AQ (Philips/Hewlett Packard, Andover, Mass) and ACUSON Sequoia Echo C256 (Siemens, New York, NY) ultrasound systems. The detailed characteristics of the patients are shown in Table 1.

Other heart valves were also evaluated during the echocardiographic examinations. We did not observe any indications for the replacement/plastics of the mitral and/or tricuspid valves in the examinations. The frequencies of coexistence of other heart valve defects are presented in Table 1.

\section{Surgical Intervention}

Each patient included in the study underwent AVR with extracorporeal circulation. After removal of the native valve, all patients were implanted with mechanical valves from St Jude Medical (St Paul, Minn). Valve sizes ranged from 19 to $31 \mathrm{~mm}$. All patients underwent AVR at normothermia with the use of antegrade cold crystalloid St Thomas' Hospital cardioplegic solution No. 2 $\left(4^{\circ} \mathrm{C}-6^{\circ} \mathrm{C}\right)$.

\section{Atrial Fibrillation Evaluation}

Postoperative paroxysmal AF was diagnosed on the basis of multiple electrocardiographic examinations and confirmed in the 24hour Holter monitoring. We considered paroxysmal AF when the arrhythmia reverted spontaneously or after treatment to sinus rhythm within 1 week.

\section{Statistical Analysis}

Statistical analyses were performed with STATISTICA PL 7.0 (StatSoft, Cracow, Poland) and SPSS 12.0 Software (SPSS Inc, Chicago, Ill). Normality was tested using the Shapiro-Wilk test. The association between the potential risk factors and the mortality rate was first evaluated by univariate analysis. For categoric variables, the chi-square test was used. The diagnostic utility of continuous risk factors was estimated through the use of receiver operating characteristic curves. The results were expressed in terms of the area under the curve with a $95 \%$ confidence interval for this area. Factors significant to at least a $P$ value less than .10 were then analyzed using multivariate logistic regression (odds ratio, $\pm 95 \%$ confidence interval, $P$ value), which was used to identify the independent clinical predictors of postoperative AF. 
TABLE 1. Detailed characteristics of the 300 patients included in the study

\begin{tabular}{|c|c|c|c|}
\hline & AS & $\mathbf{A R}$ & $P$ value \\
\hline $\mathrm{n}$ & 150 & 150 & - \\
\hline $\operatorname{Sex}(M / F) n(\%)$ & $73(48.7 \%) / 77(51.3 \%)$ & $70(46.7 \%) / 80(53.3 \%)$ & - \\
\hline Age (y) & $63.33 \pm 9.85$ & $59.61 \pm 10.37$ & $<.05$ \\
\hline Weight (kg) & $74.17 \pm 13.98$ & $72.42 \pm 11.81$ & NS \\
\hline BMI $\left(\mathrm{kg} / \mathrm{m}^{2}\right)$ & $27.35 \pm 4.35$ & $26.57 \pm 3.81$ & .02 \\
\hline BSA & $1.89 \pm 0.19$ & $1.86 \pm 0.11$ & $<.05$ \\
\hline Mean gradient & $50.88 \pm 23.7$ & - & - \\
\hline Maximum gradient & $86.54 \pm 20.6$ & - & - \\
\hline $\operatorname{LVEF}(\mathrm{cm})$ & $49.42 \pm 10.47$ & $48.99 \pm 9.47$ & NS \\
\hline LVESd $(\mathrm{cm})$ & $3.48 \pm 0.73$ & $4.27 \pm 0.85$ & $<.001$ \\
\hline LVEDd (cm) & $5.12 \pm 0.77$ & $5.97 \pm 0.94$ & $<.001$ \\
\hline ESIVST (cm) & $1.8 \pm 0.2$ & $1.65 \pm 0.17$ & $<.005$ \\
\hline EDIVST (cm) & $1.43 \pm 0.16$ & $1.31 \pm 0.15$ & $<.001$ \\
\hline LAd (cm) & $4.2 \pm 0.58$ & $4.42 \pm 0.66$ & $<.05$ \\
\hline \multicolumn{4}{|l|}{ MR n (\%) } \\
\hline 0 degree & $58(38.67 \%)$ & $49(32.67 \%)$ & NS \\
\hline I degree & $58(38.67 \%)$ & $60(40.0 \%)$ & NS \\
\hline I/II degree & $21(14.0 \%)$ & $13(8.67)$ & $<.02$ \\
\hline II degree & $7(4.67 \%)$ & $26(17.33)$ & $<.001$ \\
\hline II/III degree & $6(4.0 \%)$ & $2(1.33)$ & NS \\
\hline \multicolumn{4}{|l|}{$\operatorname{TR} \mathrm{n}(\%)$} \\
\hline 0 degree & $28(18.7 \%)$ & $22(14.7 \%)$ & NS \\
\hline I degree & $38(25.33 \%)$ & $27(18.0 \%)$ & $<.01$ \\
\hline I/II degree & $57(38.0 \%)$ & $54(36.0 \%)$ & NS \\
\hline II degree & $21(14.0 \%)$ & $40(26.7 \%)$ & $<.01$ \\
\hline II/III degree & $6(4.0 \%)$ & $7(4.67 \%)$ & NS \\
\hline $\mathrm{AH} \cap(\%)$ & $94(62.67 \%)$ & $101(67.33 \%)$ & NS \\
\hline $\mathrm{DM} n(\%)$ & $29(19.33 \%)$ & $31(20.67 \%)$ & NS \\
\hline \multicolumn{4}{|l|}{$\mathrm{HF} n(\%)$} \\
\hline LVEF $\geq 50 \%$ & 77 & 80 & \\
\hline LVEF $<35-50 \%>$ & 45 & 47 & \\
\hline LVEF $\leq 35 \%$ & 28 & 23 & NS \\
\hline RF n (\%) & $5(3.33 \%)$ & $6(4.0 \%)$ & NS \\
\hline
\end{tabular}

$A S$, Aortic stenosis; $A R$, aortic regurgitation; $B S A$, body surface area; $B M I$, body mass index; $L V E F$, left ventricle ejection fraction; $L V E S d$, left ventricular end-systolic diameter; $L V E D$, left ventricular end-diastolic diameter; ESIVST, end-systolic intraventricular septum thickness; EDIVST, end-diastolic intraventricular septum thickness; $L A d$, left atrium dimension; $M R$, mitral regurgitation; $T R$, tricuspid regurgitation; $A H$, arterial hypertension; $D M$, diabetes mellitus; $H F$, heart failure; $R F$, renal failure; $N S$, not significant.

\section{Results}

Postoperative AF developed in 131 patients (43.7\%), including 62 patients with aortic stenosis (41.3\%) and 69 patients with aortic regurgitation $(46.0 \%)$. The characteristics of patients with aortic stenosis or regurgitation and AF are presented and compared with those of patients without AF in Tables 2 and 3.

\section{Patients With Aortic Stenosis}

According to statistical analysis, factors significantly associated with AF in patients who underwent AVR for aortic stenosis were as follows: heart failure in the medical history $(P<.001)$, age $\geq 70$ years $(P<.001)$, BMI both $\geq 30$ $\mathrm{kg} / \mathrm{m}^{2}$ and $\leq 21 \mathrm{~kg} / \mathrm{m}^{2}(P<.05$ and $P<.001$, respectively), maximal transvalvular gradient $\geq 85 \mathrm{~mm} \mathrm{Hg}(P<$
$.001), \mathrm{LVEF} \leq 50 \%(P<.001)$, ESIVST $\geq 1.8 \mathrm{~cm}(P<$ $.005)$ and EDIVST $\geq 1.4 \mathrm{~cm}(P<.05)$, insignificant mitral regurgitation $(P<.02)$ in the preoperative period, and $\mathrm{LVEF} \leq 50 \%(P<.001)$ and ESIVST $\geq 1.8 \mathrm{~cm}(P<.02)$ in the early postoperative period. Postoperative AF, in comparison with the conditions of the remaining 88 patients without postoperative AF, was associated with the following: increase in the length of intensive care unit (ICU) and hospital stay $(3.26 \pm 1.54$ days vs $2.96 \pm 1.17$ days, respectively, $P<.01$, and $13.79 \pm 6.27$ vs $11.92 \pm 5.64$ days, respectively, $P<.001)$; greater incidence of stroke (5 [8.1\%] and 4 [4.5\%] events in $\mathrm{AF}(+)$ and $\mathrm{AF}(-)$, respectively, $P<.01$ ); low output syndrome (17 [27.4\%] and 22 [25\%] events in $\mathrm{AF}(+)$ and $\mathrm{AF}(-)$, respectively, $P<.05)$; 
TABLE 2. Detailed characteristics of patients with aortic stenosis and atrial fibrillation $[A F(+)=62]$ compared with those of patients without atrial fibrillation $[A F(-)=88]$ : Univariate statistical analysis

\begin{tabular}{|c|c|c|c|}
\hline & $A F(+) n(\%)$ & $A F(-)$ n (\%) & $P$ value \\
\hline $\operatorname{Sex}(M / F) n(\%)$ & $43(69.4) / 19(30.6)$ & $34(38.6) / 54(61.4)$ & NS \\
\hline Weight (kg) & $72.5 \pm 11.8$ & $72.2 \pm 12.1$ & NS \\
\hline \multicolumn{4}{|l|}{ Preoperative risk factors } \\
\hline $\mathrm{BMI}\left(\mathrm{kg} / \mathrm{m}^{2}\right)$ & $26.9 \pm 6.5$ & $26.3 \pm 3.8$ & $<.05$ \\
\hline Maximum gradient & $88.6 \pm 21.2$ & $84.4 \pm 24.6$ & $<.001$ \\
\hline $\operatorname{LVEF}(\mathrm{cm})$ & $45.4 \pm 9.7$ & $48.9 \pm 11.4$ & $<.001$ \\
\hline LVESd (cm) & $3.51 \pm 0.71$ & $3.49 \pm 0.67$ & NS \\
\hline LVEDd (cm) & $5.13 \pm 0.87$ & $5.09 \pm 0.99$ & NS \\
\hline ESIVST (cm) & $1.85 \pm 0.21$ & $1.81 \pm 0.18$ & $<.005$ \\
\hline $\mathrm{HA} n(\%)$ & $39(62.9)$ & $55(62.5)$ & NS \\
\hline DM n (\%) & $12(19.4)$ & $17(19.3)$ & NS \\
\hline HF n (\%) & $39(62.9)$ & $34(38.6)$ & $<.001$ \\
\hline RF n (\%) & $2(3.2)$ & $3(3.4)$ & NS \\
\hline \multicolumn{4}{|l|}{ Early postoperative risk factors } \\
\hline Mean gradient & $14.01 \pm 68$ & $13.79 \pm 6.4$ & NS \\
\hline Maximum gradient & $28.1 \pm 8.8$ & $25.7 \pm 7.4$ & NS \\
\hline $\operatorname{LVEF}(\mathrm{cm})$ & $49.4 \pm 3.9$ & $52.1 \pm 8.1$ & $<.001$ \\
\hline LVESd (cm) & $3.27 \pm 0.98$ & $3.24 \pm 0.67$ & NS \\
\hline LVEDd (cm) & $4.86 \pm 0.62$ & $4.84 \pm 0.97$ & NS \\
\hline ESIVST $(\mathrm{cm})$ & $1.79 \pm 0.17$ & $1.75 \pm 0.21$ & $<.02$ \\
\hline LOS & $17(27.4)$ & $22(25.0)$ & $<.05$ \\
\hline Hospital mortality & $5(8.1)$ & $3(3.4)$ & $<.001$ \\
\hline \multicolumn{4}{|l|}{ Long-term observations* } \\
\hline Mortality & $4(7.0)$ & $5(6.3)$ & NS \\
\hline
\end{tabular}

$A F$, Atrial fibrillation; $B S A$, body surface area; $B M I$, body mass index; $L V E F$, left ventricle ejection fraction; $L V E S d$, left ventricular end-systolic diameter; $L V E D$, left ventricular end-diastolic diameter; ESIVST, end-systolic intraventricular septum thickness; EDIVST, end-diastolic intraventricular septum thickness; $L A d$, left atrium dimension; $M R$, mitral regurgitation; $T R$, tricuspid regurgitation; $A H$, arterial hypertension; $D M$, diabetes mellitus; $H F$, heart failure; $R F$, renal failure; $N S$, not significant; $I C U$, intensive care unit; $L O S$, low output syndrome. *All analyzed long-term parameters were insignificant. Respiratory complications included pleural effusion, pneumonia, atelectasis, and other conditions requiring prolonged intubation ( $>24 \mathrm{~h}$ ) or reintubation. LOS was defined as the need for high dosages of inotropic medication and/or intra-aortic balloon pumping to sustain adequate hemodynamic status.

and early postoperative death $(5[8.1 \%]$ and $3[3.4 \%]$ deaths in $\mathrm{AF}(+)$ and $\mathrm{AF}(-)$, respectively, $P<.001)$ (Table 2). Multivariate logistic regression analysis identified 7 independent predictors of postoperative paroxysmal AF in patients with aortic stenosis who underwent AVR: advanced age, history of heart failure, BMI $\leq 21 \mathrm{~kg} / \mathrm{m}^{2}$, maximal transvalvular gradient $\geq 85 \mathrm{~mm} \mathrm{Hg}, \mathrm{LVEF} \leq 50 \%$ in the pre- and early postoperative periods, and ESIVST $\geq 1.8 \mathrm{~cm}$ before the surgery (Table 3 ).

\section{Patients With Aortic Regurgitation}

According to statistical analysis, factors significantly associated with $\mathrm{AF}$ in patients who underwent AVR for aortic regurgitation were as follows: age $\geq 70$ years $(P<.05)$, LVEF 
TABLE 3. Preoperative and early postoperative significant risk factors of atrial fibrillation after aortic valve replacement for aortic stenosis

\begin{tabular}{llll}
\hline Predictor & $\boldsymbol{P}$ value & Adjusted OR & 95\% Cl \\
\hline Preoperative & & & \\
Age $\geq 70 \mathrm{y}^{*}$ & $<.001$ & 4.5 & $1.7-5.2$ \\
$\mathrm{BMI} \geq 30 \mathrm{~kg} / \mathrm{m}^{2}$ & $<.05$ & 1.7 & $1.1-2.7$ \\
$\mathrm{BMI} \leq 21 \mathrm{~kg} / \mathrm{m}^{2 *}$ & $<.001$ & 3.9 & $2.1-4.6$ \\
Maximum gradient $\geq 85 \mathrm{~mm}$ & $<.001$ & 3.7 & $1.6-12.4$ \\
$\mathrm{Hg}^{*}$ & $<.001$ & 5.1 & $1.7-9.6$ \\
$\mathrm{LVEF} \leq 50 \% *$ & $<.005$ & 2.9 & $1.5-4.3$ \\
ESIVST $\geq 1.8 \mathrm{~cm}^{*}$ & $<.05$ & 1.5 & $1.2-1.9$ \\
EDIVST $\geq 1.4 \mathrm{~cm}$ & $<.02$ & 1.9 & $1.1-4.7$ \\
MR & $<.001$ & 5.5 & $1.6-6.4$ \\
$\mathrm{HF}$ & & & \\
Early postoperative & & & \\
LVEF $\leq 50 \% \%^{*}$ & $<.001$ & 4.4 & $1.6-11.1$ \\
ESIVST $\geq 1.8 \mathrm{~cm}$ & $<.02$ & 1.8 & $1.2-2.4$ \\
\hline
\end{tabular}

$O R$, Odds ratio; $C l$, confidence interval; $B M I$, body mass index; $L V E F$, left ventricle ejection fraction; ESIVST, end-systolic intraventricular septum thickness; EDIVST, end-diastolic intraventricular septum thickness; MR, mitral regurgitation; $H F$, heart failure. *Independent risk factors.

$\leq 50 \%(P<.005)$, left ventricular end-systolic diameter $\geq$ $4.15 \mathrm{~cm}(P<.02)$, EDIVST $\geq 1.35 \mathrm{~cm}(P<.05)$, LAd $\geq$ $4.25 \mathrm{~cm}(P<.005)$, insignificant mitral regurgitation $(P<.01)$ in the preoperative period, essential arterial hypertension $\geq$ 160/100 $\mathrm{mm} \mathrm{Hg}$ (second-degree hypertension according to the European Society of Hypertension/European Society of Cardiology 2007 guidelines) $(P<.001)$, diabetes mellitus $(P<$ $.001)$, heart failure in the history $(P<.001)$, and LVEF $\leq 50 \%$ $(P<.05)$ and $\mathrm{LAd} \geq 4.15 \mathrm{~cm}(P<.005)$ in the early postoperative period. Postoperative $\mathrm{AF}$, in comparison with the conditions of the remaining 81 patients without postoperative $\mathrm{AF}$, was associated with an increase in the length of ICU and hospital stay $(4.28 \pm 1.38$ days vs $3.45 \pm 1.33$ days, respectively, $P<.001$, and $15.14 \pm 2.21$ days vs $12.93 \pm 3.36$ days, respectively, $P<.001$ ); a greater incidence of stroke (5 [7.2\%] and 3 [3.7\%] events in $\mathrm{AF}(+)$ and $\mathrm{AF}(-)$, respectively, $P<$ $.001)$; low output syndrome (24 [34.8\%] and 23 [28.4\%] events in $\mathrm{AF}(+)$ and $\mathrm{AF}(-)$, respectively, $P<.02)$; and early postoperative death $(7[10.1 \%]$ and 4 [4.9\%] deaths in $\mathrm{AF}(+)$ and $\mathrm{AF}(-)$, respectively, $P<.001)$. By comparing the longterm mortality, we observed a persistent significant difference between groups (6 [9.7\%] and 3 [3.9\%] deaths in $\mathrm{AF}(+)$ and AF $(-)$, respectively, $P<.001$ ) (Table 4). Multivariate logistic regression analysis identified 7 independent predictors of postoperative paroxysmal $\mathrm{AF}$ in patients with aortic regurgitation: history of heart failure, diabetes mellitus and essential arterial hypertension, $\mathrm{LVEF} \leq 50 \%$, insignificant mitral regurgitation in the preoperative period, and $\operatorname{LAd} \geq 4.25 \mathrm{~cm}$ and $\geq$ $4.15 \mathrm{~cm}$ in the pre- and early postoperative periods, respectively (Table 5).

\section{Combined Group of Patients}

According to statistical analysis, factors significantly associated with postoperative AF in patients who underwent AVR for aortic stenosis and regurgitation were as follows: age $\geq 70$ years $(P<.05)$, LVEF $\leq 50 \%(P<.001)$, left ventricular end-systolic diameter $\geq 3.85 \mathrm{~cm}(P<.003)$ and end-diastolic diameter $\geq 5.5 \mathrm{~cm}(P<.02)$, ESIVST $\geq 1.75$ $\mathrm{cm}(P<.001)$ in the preoperative period; heart failure in the medical history $(P<.02)$, LVEF $\leq 50 \%(P<.001)$, left ventricular end-systolic diameter $\geq 3.75 \mathrm{~cm}(P<.003)$, and left ventricular end-diastolic diameter $\geq 5.35 \mathrm{~cm}(P<.05)$ in the early postoperative period; and LVEF $\leq 50 \%(P<$ $.001)$ and left ventricular end-systolic and end-diastolic diameters $\geq 3.6 \mathrm{~cm}(P<.003)$ and $\geq 5.1 \mathrm{~cm}(P<.04)$, respectively, in the long-term observations. On the basis of univariate statistical analysis, we showed a significant correlation between postoperative paroxysmal $\mathrm{AF}$ and the type of aortic valve defect $(P<.03$ for aortic regurgitation), postoperative low cardiac output syndrome $(P<.001)$, and early postoperative death $(P<.002)$. Multivariate logistic regression analysis showed that postoperative AF was an independent risk factor of early postoperative death (odds ratio $=3.9 ; 95 \%$ confidence interval $1.7-9.0 ; P<.002$ ). Postoperative $\mathrm{AF}$ was associated with an increase in the length of ICU and hospital stay (3.85 \pm 1.23 days vs 3.12 \pm 1.93 days, respectively, $P<.001$, and $14.75 \pm 2.81$ days vs $11.97 \pm 2.78$ days, respectively, $P<.001)$. Multivariate logistic regression analysis identified 6 independent predictors of postoperative paroxysmal AF in patients who underwent AVR for an aortic valve defect: low BMI $\leq 21 \mathrm{~kg} / \mathrm{m}^{2}$, LVEF $\leq 50 \%$, left ventricular end-systolic diameter $\geq 3.85$ $\mathrm{cm}$, ESIVST $\geq 1.75 \mathrm{~cm}$ in the preoperative period, and LVEF $\leq 50 \%$ in early postoperative period and the type of aortic valve defect (aortic regurgitation) (Table 6).

\section{Discussion}

$\mathrm{AF}$ is one of the most common complications after cardiosurgical operations. It contributes to the worsening of the postoperative state and prognosis and increases the length of ICU stay, hospitalization, and hospital costs considerably. ${ }^{11-13}$ For example, Kuduvalli and colleagues ${ }^{14}$ analyzed predictors of in-hospital mortality in patients who underwent AVR. Among many risk factors, such as age greater than 70 years, renal dysfunction, and heart failure, they observed that postoperative AF was a significant predictor of hospital mortality in patients after AVR. Similar outcomes were also obtained in Kvidal and colleagues' study, ${ }^{15}$ in which the authors showed that postoperative AF, advanced New York Heart Association functional class, pure aortic regurgitation, and thromboembolism before surgery decreased postoperative survival in patients who underwent AVR. Postoperative AF may also cause other lifethreatening complications, such as stroke, especially in 
TABLE 4. Detailed characteristics of patients with aortic regurgitation and atrial fibrillation $[A F(+)=69]$ in comparison with those of patients without atrial fibrillation $[\mathrm{AF}(-)=81]$ : Univariate statistical analysis

\begin{tabular}{|c|c|c|c|}
\hline & $A F(+)$ n (\%) & $A F(-)$ n (\%) & $P$ value \\
\hline $\operatorname{Sex}(M / F) n(\%)$ & $36(52.2) / 33(47.8)$ & $34(42.0) / 47(58.0)$ & NS \\
\hline Weight (kg) & $72.4 \pm 12.5$ & $71.7 \pm 11.7$ & NS \\
\hline \multicolumn{4}{|l|}{ Preoperative risk factors } \\
\hline BMI $\left(\mathrm{kg} / \mathrm{m}^{2}\right)$ & $26.5 \pm 3.5$ & $26.1 \pm 3.3$ & NS \\
\hline LVESd (cm) & $4.33 \pm 0.51$ & $4.05 \pm 0.95$ & $<.02$ \\
\hline LVEDd (cm) & $5.91 \pm 0.99$ & $5.88 \pm 0.65$ & NS \\
\hline ESIVST $(\mathrm{cm})$ & $1.64 \pm 0.15$ & $1.65 \pm 0.22$ & NS \\
\hline EDIVST (cm) & $1.3 \pm 0.14$ & $1.34 \pm 0.17$ & $<.05$ \\
\hline $\operatorname{LAd}(\mathrm{cm})$ & $4.47 \pm 0.74$ & $4.25 \pm 0.65$ & $<.005$ \\
\hline HF n (\%) & $43(62.3)$ & $27(33.3)$ & $<.001$ \\
\hline $\mathrm{RF} \mathrm{n}(\%)$ & $2(3.0)$ & $4(4.9)$ & NS \\
\hline \multicolumn{4}{|l|}{ Early postoperative risk factors } \\
\hline LVEF (cm) & $44.7 \pm 6.9$ & $47.8 \pm 6.3$ & $<.05$ \\
\hline LVESd $(\mathrm{cm})$ & $4.09 \pm 0.49$ & $3.97 \pm 0.82$ & NS \\
\hline LVEDd (cm) & $5.64 \pm 0.92$ & $5.62 \pm 0.86$ & NS \\
\hline ESIVST $(\mathrm{cm})$ & $1.62 \pm 0.15$ & $1.63 \pm 0.13$ & NS \\
\hline EDIVST (cm) & $1.3 \pm 0.15$ & $1.3 \pm 0.14$ & NS \\
\hline LAd $(\mathrm{cm})$ & $4.29 \pm 0.57$ & $4.15 \pm 0.61$ & $<.005$ \\
\hline Duration of ICU stay (d) & $4.28 \pm 1.38$ & $3.45 \pm 1.33$ & $<.001$ \\
\hline Duration of hospital stay (d) & $15.14 \pm 2.21$ & $12.93 \pm 3.36$ & $<.001$ \\
\hline
\end{tabular}

$A F$, Atrial fibrillation; $B S A$, body surface area; $B M I$, body mass index; $L V E F$, left ventricle ejection fraction; $L V E S d$, left ventricular end-systolic diameter; LVEDd, left ventricular end-diastolic diameter; ESIVST, end-systolic intraventricular septum thickness; EDIVST, end-diastolic intraventricular septum thickness; $L A d$, left atrium dimension; $M R$, mitral regurgitation; $T R$, tricuspid regurgitation; $A H$, arterial hypertension; $D M$, diabetes mellitus; $H F$, heart failure; $R F$, renal failure; $N S$, not significant; $I C U$, intensive care unit; $L O S$, low output syndrome. *All analyzed long-term parameters were insignificant.

patients with prosthetic valves. In Ruel and colleagues' study, ${ }^{16}$ the authors evaluated the determinants of stroke in patients after AVR. They proved that postoperative AF, a history of coronary disease, and tilting-disc mechanical prostheses were independent predictors of embolic stroke after AVR, which essentially worsened the prognosis and prolonged the hospitalization. These results were confirmed in our study. On the basis of univariate statistical analysis, we showed that postoperative AF significantly increased the incidence of stroke and low output syndrome in patients with aortic stenosis and regurgitation. Furthermore, postoperative AF was essentially associated with the risk of post- operative mortality in both groups of patients. However, on multivariate statistical analysis in each of the investigated groups of patients, for whom mortality was the end point and $\mathrm{AF}$ was one of the independent variables, we have not observed postoperative AF to be a significant predictor of postoperative mortality, probably because of the small number of samples in each group. However, by analyzing a combined group of patients, we showed that postoperative AF was an independent risk factor of early postoperative mortality (odds ratio $=3.9, P<.002$ ). In both analyzed groups of patients, postoperative AF was connected with a significant longer duration of ICU stay and hospitalization. 
TABLE 5. Preoperative and early postoperative significant risk factors of atrial fibrillation after aortic valve replacement for aortic regurgitation

\begin{tabular}{llcl}
\hline Predictor & $\boldsymbol{P}$ value & Adjusted OR & $\mathbf{9 5 \%} \mathbf{~ C l}$ \\
\hline Preoperative & & & \\
Age $\geq 70 \mathrm{y}$ & $<.05$ & 1.8 & $1.2-4.2$ \\
LVEF $\leq 50 \%$ * & $<.005$ & 3.7 & $1.6-6.7$ \\
LVESd $\geq 4.15 \mathrm{~cm}$ & $<.02$ & 1.7 & $1.1-3.6$ \\
EDIVST $\geq 1.35 \mathrm{~cm}$ & $<.05$ & 1.7 & $1.2-2.4$ \\
LAd* $\geq 4.25 \mathrm{~cm}$ & $<.005$ & 4.1 & $1.8-8.6$ \\
$\mathrm{MR}^{*}$ & $<.01$ & 2.5 & $1.6-3.9$ \\
$\mathrm{AH}^{*}$ & $<.001$ & 3.3 & $1.5-7.7$ \\
DM* & $<.001$ & 2.6 & $1.6-4.2$ \\
$\mathrm{HF}^{*}$ & $<.001$ & 4.5 & $1.6-9.4$ \\
Early postoperative & & & \\
LVEF $\leq 50 \%$ & $<.05$ & 1.9 & $1.3-4.7$ \\
LAd* $\geq 4.15$ & $<.005$ & 2.9 & $1.7-4.5$ \\
\hline
\end{tabular}

$O R$, Odds ratio; $C l$, confidence interval; $L V E F$, left ventricle ejection fraction; $\angle V E S d$, left ventricular end-systolic diameter; $L V E D d$, left ventricular enddiastolic diameter; EDIVST, end-diastolic intraventricular septum thickness; $L A d$, left atrium dimension; $M R$, mitral regurgitation; $A H$, arterial hypertension; $D M$, diabetes mellitus; $H F$, heart failure. *Independent risk factors.

Few studies present predictors of postoperative AF in patients who underwent AVR. In Orlowska-Baranowska and colleagues' study, ${ }^{17}$ the authors identified age, New York Heart Association functional class, history of preoperative paroxysmal AF, left ventricular mass index $>300$ supraventricular beats on 24-hour electrocardiography before surgery, presence of supraventricular tachycardia, supraventricular tachycardia of $>5$ beats, or a rate $>120$ beats/min as risk factors of postoperative paroxysmal AF. By using multivariate analysis, they identified the following 4 variables as independent predictors: age, history of paroxysmal AF, presence of $>300$ supraventricular beats $/ 24$ hours, and presence of supraventricular tachycardia. In Ducceschi and colleagues' study, ${ }^{18}$ the authors included 302 patients and divided them into 2 groups according to the absence or evidence of post-AVR AF. Post-AVR paroxysmal AF occurred in $19 \%$ of patients. They noticed that AF post-AVR was associated with advanced age, left atrial enlargement, preoperative episodes of paroxysmal AF, use of a warm blood cardioplegic solution and normothermia, administration of inotropic agents, prolonged assisted ventilation, electrolyte imbalance, and atrioventricular and intraventricular conduction disorders. By using multivariate logistic regression analysis, the authors identified age, left atrial enlargement, a history of paroxysmal AF, and postoperative electrolyte imbalance as independent correlates of $\mathrm{AF}$, whereas the use of hypothermia seemed to be a protective factor. These results are partially consistent with the outcomes obtained in our study. Both pre- and early postoperative LVEF $\leq 50 \%$ and history of heart failure were
TABLE 6. Preoperative and early postoperative independent risk factors of atrial fibrillation after aortic valve replacement

\begin{tabular}{llll}
\hline Predictor & $\boldsymbol{P}$ value & Adjusted OR & $\mathbf{9 5 \%} \mathbf{~ C I}$ \\
\hline Preoperative & & & \\
$\quad$ Type of aortic defect, AR & $<.03$ & 1.7 & $1.1-2.6$ \\
BMI $\leq 21 \mathrm{~kg} / \mathrm{m}^{2}$ & $<.004$ & 4.1 & $1.6-10.7$ \\
LVEF $\leq 50 \%$ & $<.03$ & 1.7 & $1.1-2.7$ \\
LVESd $\geq 3.85 \mathrm{~cm}$ & $<.008$ & 1.9 & $1.2-3.0$ \\
$\quad$ ESIVST $\geq 1.75 \mathrm{~cm}$ & $<.02$ & 1.7 & $1.1-2.7$ \\
Early postoperative & & & \\
$\quad$ LVEF $\leq 50 \%$ & $<.001$ & 2.8 & $1.8-4.5$ \\
\hline
\end{tabular}

$O R$, Odds ratio; $C l$, confidence interval; $A R$, aortic regurgitation; $B M I$, body mass index; $L V E F$, left ventricular ejection fraction; $L V E S d$, left ventricular end-systolic diameter; ESIVST, end-systolic intraventricular septum thickness.

independent predictors of postoperative AF. We also noticed that changes of some hemodynamic parameters, such as ESIVST and EDIVST for patients with aortic stenosis and ESIVST, left ventricular end-systolic diameter, and LAd for aortic regurgitation, significantly influenced the appearance of postoperative AF.

Despite the risk factors presented, we also found some other predictors that have not been mentioned in the available studies, for example, low BMI and maximal transvalvular gradient for patients with aortic stenosis, and a history of insignificant mitral regurgitation, essential atrial hypertension, and diabetes mellitus for patients with aortic regurgitation. Low BMI as an independent predictor of postoperative $\mathrm{AF}$ in the patients with aortic stenosis and the combined group of patients who underwent AVR, irrespective of the type of valve defect, seems to be exceptionally interesting, because these results confirmed previous reports suggesting that low BMI may worsen the prognosis and increase the risk of cardiovascular events and mortality in patients with heart diseases. ${ }^{19-22}$ Furthermore, in the other study we observed that low BMI and the previously stated essential arterial hypertension were also independent predictors of postoperative in-hospital death in patients who underwent AVR. ${ }^{23-25}$

In the present study, we also analyzed predictors of postoperative paroxysmal $\mathrm{AF}$ in the combined group of 300 patients who underwent AVR. We showed that in addition to few other significant predictors, the type of aortic valve defect, aortic regurgitation, was itself an independent risk factor of postoperative AF. There are no available studies indicating that the type of valve defect, aortic regurgitation, might influence postoperative AF occurrence irrespective of other pre- and postoperative risk factors. It means that patients with aortic regurgitation qualified for AVR should be treated as patients with a higher risk of postoperative AF. Further studies are necessary to confirm these results. 
The present study has some limitations, which are mainly connected with the number of patients included in the study and consequently the number of patients with postoperative AF. We also did not analyze many other potential AF predictors, especially from the intraoperative period. However, we were aware that it would have been difficult to examine all possible risk factors, so we focused specifically on the hemodynamic parameters and the impact of postoperative $\mathrm{AF}$ on them.

\section{Conclusions}

We separated the following independent risk factors of postoperative AF occurrence: advanced age, history of heart failure, low BMI, maximal transvalvular gradient, low ejection fraction, and preoperative ESIVST for patients with aortic stenosis; and history of heart failure, diabetes mellitus and essential arterial hypertension, low LVEF, insignificant mitral regurgitation in the preoperative period, and high LAd for patients with aortic regurgitation. In the combined group of patients, the following predictors were significant and independent: type of valve defect (aortic regurgitation), low BMI, low LVEF, left ventricular end-systolic diameter, and ESIVST in the preoperative period, and low LVEF early after AVR. A large, multicenter study should be performed to confirm these results.

The study may have an important influence on the management of patients who undergo AVR. On the basis of the separated risk factors, all patients should be preoperatively classified to applicable groups of risk of postoperative AF appearance, and the prophylactic treatment (pre- and postoperative) should be administered in the highest risk group of patients. It may essentially decrease the rate of complications and deaths, and the costs of postoperative medical care.

\section{References}

1. Banach M, Okoński P, Rysz J, Piechowiak M, Zasłonka J. Prevention and treatment of atrial fibrillation following cardiac surgery. Pol Merkur Lekarski. 2005;19:794-9.

2. Banach M, Rysz J, Drozdz J, Misztal M, Barylski M, Okonski P, et al. Risk factors of atrial fibrillation following coronary artery bypass grafting-preliminary report. Circ J. 2006;70:438-41.

3. Creswell LL, Damiano RJ. Postoperative atrial fibrillation: an old problem crying for new solutions. J Thorac Cardiovasc Surg. 2001;12:638-41.

4. Kato T, Yamashita T, Sagara K, Iinuma H, Fu LT. Progressive nature of paroxysmal atrial fibrillation: observations from a 14-year follow-up study. Circ J. 2004;68:568-72.

5. Magee MJ, Herbert MA, Dewey TM, Edgerton JR, Ryan WH, Prince $\mathrm{S}$, et al. Atrial fibrillation after coronary artery bypass grafting surgery: development of a predictive risk algorithm. Ann Thorac Surg. 2007; 83:1707-12.

6. Fuster V, Ryden LE, Cannom DS, Crijns HJ, Curtis AB, Ellenbogen KA, et al. Task Force on Practice Guidelines, American College of Cardiology/American Heart Association; Committee for Practice Guidelines, European Society of Cardiology; European Heart Rhythm Association; Heart Rhythm Society. ACC/AHA/ESC 2006 guidelines for the management of patients with atrial fibrillation-executive summary: a report of the American College of Cardiology/American Heart Association Task Force on practice guidelines and the European So- ciety of Cardiology Committee for Practice Guidelines (Writing Committee to Revise the 2001 Guidelines for the Management of Patients with Atrial Fibrillation). Eur Heart J. 2006;27:1979-2030.

7. Halonen J, Halonen P, Jarvinen O, Taskinen P, Auvinen T, Tarkka M, et al. Corticosteroids for the prevention of atrial fibrillation after cardiac surgery: a randomized controlled trial. JAMA. 2007;297:1562-7.

8. Piechowiak M, Banach M, Ruta J, Barylski M, Rysz J, Bartczak K, et al. Risk factors of atrial fibrillation in adult patients in long-term observation following surgical closure of atrial septal defect type II. Thorac Cardiovasc Surg. 2006;54:259-63.

9. Hosokawa K, Nakajima Y, Umenai T, Ueno H, Taniguchi S, Matsukawa T, et al. Predictors of atrial fibrillation after off-pump coronary artery bypass graft surgery. Br J Anaesth. 2007;98:575-80.

10. Banach M, Misztal M, Goch A, Rysz J, Goch JH. Predictors of atrial fibrillation in patients following isolated surgical revascularization. A metaanalysis of 9 studies with 28786 patients. Arch Med Sci. 2007; 3:229-39.

11. Mistiaen W, Van Cauwelaert PH, Sys SU, Muylaert PH, Harrisson F, Bortier $\mathrm{H}$. Role of age, gender and association of CABG on long-term results after aortic valve replacement with a Carpentier-Edwards bioprosthesis in the elderly. J Cardiovasc Surg. 2003;44:701-6.

12. Banach M, Ostrowski S, Zasłonka J, Iwaszkiewicz A, Barylski M, Irzmański $\mathrm{R}$, et al. Is there a relation between preoperative atrial fibrillation and increased mortality after cardiac surgery? Folia Cardiol. 2005;12(Suppl D):102-4.

13. Mistiaen W, Van Cauwelaert P, Muylaert P, Wuyts F, Harrisson F, Bortier H. Risk factors and survival after aortic valve replacement in octogenarians. J Heart Valve Dis. 2004;13:538-44.

14. Kuduvalli M, Grayson AD, Au J, Grotte G, Bridgewater B, Fabri BM. A multi-centre additive and logistic risk model for in-hospital mortality following aortic valve replacement. Eur J Cardiothorac Surg. 2007;31:607-13.

15. Kvidal P, Bergstrom R, Malm T, Stahle E. Long-term follow-up of morbidity and mortality after aortic valve replacement with a mechanical valve prosthesis. Eur Heart J. 2000;21:1099-111.

16. Ruel M, Masters RG, Rubens FD, Bedard PJ, Pipe AL, Goldstein WG, et al. Late incidence and determinants of stroke after aortic and mitral valve replacement. Ann Thorac Surg. 2004;78:77-83.

17. Orlowska-Baranowska E, Baranowski R, Michalek P, Hoffman P, Rywik T, Rawczylska-Englert I. Prediction of paroxysmal atrial fibrillation after aortic valve replacement in patients with aortic stenosis: Identification of potential risk factors. J Heart Valve Dis. 2003;12:136-41.

18. Ducceschi V, D’Andrea A, Galderisi M, De Feo M, Limongelli G, Mercurio B, et al. Risk predictors of paroxysmal atrial fibrillation following aortic valve replacement. Ital Heart J. 2001;2:507-12.

19. Perrotta S, Nilsson F, Brandrup-Wognsen G, Jeppsson A. Body mass index and outcome after coronary artery bypass surgery. J Cardiovasc Surg (Torino). 2007;48:239-45.

20. Nicoletti I, Cicoira M, Morando G, Benazzi C, Prati D, Morani G, et al. Impact of body mass index on short-term outcome after acute myocardial infarction: does excess body weight have a paradoxical protective role? Int J Cardiol. 2006;107:395-9.

21. Potapov EV, Loebe M, Anker S, Stein J, Bondy S, Nasseri BA, et al Impact of body mass index on outcome in patients after coronary artery bypass grafting with and without valve surgery. Eur Heart $J$. 2003;24:1933-41.

22. Engelman DT, Adams DH, Byrne JG, Aranki SF, Collins JJ, Couper GS, et al. Impact of body mass index and albumin on morbidity and mortality after cardiac surgery. J Thorac Cardiovasc Surg. 1999;118:866-73.

23. Banach M, Okoński P, Końider A, Irzmański R, Rysz J, Olszewski R, et al. Aortic valve replacement in patients with heart failure. Pol Merkur Lekarski. 2006;20:642-5.

24. Banach M, Goch A, Barylski M, Rysz J, Kowalski J, Goch JH. Low $\mathrm{BMI}$ as an independent risk factor of death in patients with severe heart failure subjected to aortic valve replacement. Eur J Heart Fail. 2007; 6(Suppl 1):21.

25. Banach M, Goch A, Misztal M, Rysz J, Barylski M, Jaszewski R, et al. Low output syndrome following aortic valve replacement. Predictors and prognosis. Arch Med Sci. 2007;3:117-22. 